\title{
The Predicament of Spreading Chinese Traditional Culture and Methods of Solving the Problem
}

\author{
Haoxin Huo* \\ School of Entrepreneurship \\ Wuhan University of Technology \\ Wuhan City, Hubei Province, China
}

\author{
Yonghui Li \\ School of Foreign Language \\ Jilin University \\ Changchun City, Jilin Province, China
}

\author{
Ruyi Wang \\ School of Entrepreneurship \\ Wuhan University of Technology \\ Wuhan City, Hubei Province, China
}

\begin{abstract}
China has extensive and profound, long-standing and well-established traditional culture. Unfortunately, it now faces the difficulty of spreading itself in this time. There are many people who lack knowledge and even self-identity of Chinese traditional culture. The spread of Chinese traditional culture has encountered great dilemma, which is a ramification of many causes, among them, the top three are listed here. First of all, different subjects, such as the government, schools and the culture industry itself, have different shortcomings and troubles. Second, media only plays a pessimistic role in the spread of traditional culture, which is of little help to solve the problem. Third is the block of social environment, both economically and culturally. In allusion to the reasons, the author came up with methods from aspects of the industry itself, the government, and society. Hopefully to remove the dilemma of traditional culture communication, and to protect and inherit our traditional culture.
\end{abstract}

Keywords—-traditional culture; spread; predicament; measures

\section{INTRODUCTION}

The Chinese traditional culture is an all-embracing concept which could be subdivided into material culture, system culture, spirit culture, and so on.

The history of more than five thousand years endows Chinese people with rich traditional culture resources. However, our traditional culture is facing the danger of being ignored and forgotten, and even extinction. At the moment, our traditional culture is on the shelf, cared by few people. Many distinctive traditional skills lack successors and are almost lost.

According to investigations, though the majority of Chinese people have basic knowledge of their traditions, deeper insight and clearer cognition are still needed. Because many people have no idea of the intension and spirit of our traditional culture, and only a few have the desire to know more.

National innovation and entrepreneurship training program for college students S201910497097
There are various causes of the current dilemma of traditional culture communication, and different scholars have put forward different measures. Hu Zhengrong believes that during the process of spread, traditional culture is unproperly transferred and has advertised. There also exists insufficient understanding of the value of traditional culture.[1] In Hao Lili's point of view, our traditional culture has been spread from the perspective of "others", which results in the lack of audience and the limited effect of spread. [2]Scholars tend to focus on the problems during the spread, such as the form, content and the process of the spread. However, the environment and the audience of the communication are largely neglected. When analyzing the causes of the dilemma, it is necessary to take communication parties, channels, environment and interactive relations into consideration.

In allusion to the causes of the spread dilemma, many scholars have raised constructive advice. According to Pang Jingjun, we should dig out and sort out valuable resource of traditional culture, extracting useful element and undergo modern transformation. [3]Chang Huaiyun suggested we make full use of new media, such as the internet, and seek more various ways of spreading.[4] Many other scholars attach importance to the relation among traditional culture, modern design and society responsibility in order to endow aesthetic style and useful function to the final product and to realize traditional culture's sustainable development in real life.

\section{Reasons of The Dilemma of Promoting Chinese TRADITIONAL CULTURE}

\section{A. Problems of Different Subjects}

1) The inherent imperfection of cultural industry

Traditional culture is inevitably stamped by past eras, and part of it do not accord with the mainstream and needs of present time. Unfortunately, they are poured into modern life without distinction and transformation. Thus, people have difficulty understanding them, let alone accepting. 
Since our world becomes more and more open and free and people get ideological progress. The dross of traditional culture can hardly meet people's need, causing aversion and protest.

Traditional culture is promoted without market investigation, ignoring people's requirement. Additionally, traditional culture is not well connected with characteristics of times and the elements of the two are sometimes blends in the wrong way. As we can imagine, it is difficult for people to accept the publicity and product of this kind, and they can hardly have enthusiasm to consume. As a result, good financial benefit is out of reach. The publicity of traditional culture depends on continuous socialization promotion, the latter is then supported by financial benefit.

What's more, the way we inherent traditional culture has its limitations. In most cases, our traditional culture is handed downed in verbal form and remembered in mind. Although this one-to-one teaching guarantee the integrity and the effect of learning, it greatly limits the scale of promotion.

2) Insufficient Protection and Improper Advertise of Government

In recent years, although the government has issued a series of acts to promote the development of traditional culture, for a long time, the protection and inheritance of traditional culture has not been paid enough attention.

A small number of propagandas also tend to target at the public in the one-way process, with obvious political color, ignoring the appeal of the public, greatly declining the effect.

\section{3) Flaws in School Education}

For a long time, schools have squinted educate students with booklore, such as knowledge of natural science and social science, while neglecting the inheritance of traditional culture. In schools, traditional culture is regarded as nonessentials and is also taught in the cramming method. For example, teachers always give lectures and explain the meaning of ancient poetry in Chinese class according to the tutorial book. As a result, students' self-understanding is badly restricted and their enthusiasm in traditional culture is destroyed.

\section{B. Limitations of Media Communication}

\section{1) Limitations of traditional communication}

The way of spreading traditional culture is not various, and it can hardly fully convey the charm of traditional culture. It also limits the scope and speed of traditional culture promotion.

Traditional culture also shows obvious deficiencies in the channels of communication. In daily life, there is very little advertise about traditional culture. Instead, Western culture always appears in front of the public.

\section{2) The Problem in Mixing Traditional Culture and} Modern Media

With the rapid development of modern media technology, the modernization of traditional culture has once again been in trouble: on the one hand, the rise of modern media has taken up the living space of traditional media; on the other hand, traditional culture has not effectively used modern media to spread itself. The integration process of the two is at a low speed.

Speaking of the content of communication, new media communication has its own limitations. Although it has strong information timeliness, the content lacks in-depth analysis. Given that traditional ideology possesses certain depth of thinking, it is difficult for us to guarantee the professionalism of the content of traditional culture.

The supervision of new media is a big problem. In terms of communication quality, the current new media platform carries a large amount of traditional cultural information, and the quality of the content is difficult to guarantee. Information on the Internet is sometimes misleading, making it difficult for common people to distinguish between the true and the fake.

In terms of communication efficiency, students are easier to be distracted when learning online and have lower learning efficiency. The study of traditional culture requires a certain degree of patience and perseverance. The learning of traditional cultures needs not only book knowledge but also practice.

\section{3) Lack of Professional Talents}

The communicator is the key to information dissemination, directly influencing the quality of the content of the communication, and thus decides how well the public accept it. Professionals of traditional cultural do not usually station on communication platforms. Therefore, most of the communication course is carried out by professional communication talents, such as TV anchors and hosts. At present, most communication talents do not possess abundant and systematic traditional cultural knowledge. Thus, only a very small number of people can produce traditional cultural information with depth and high quality.

In short, the fact that we lack professional communication talents who also high level of traditional culture quality has seriously hindered the spread of traditional culture.

\section{Social Atmosphere}

\section{1) Economic Environment}

In the context of modernization and marketization, it is not easy for traditional culture to go down a market-oriented way, and many traditional cultural products are not competitive in the market. Nowadays, most of the products on the domestic market are imported from the West. The process of design, production and sales become more and more 'Western', while elements of Chinese cultural are few. Delightfully, in recent years, Chinese traditional culture has attracted more and more attention from the world. Many international brands have added Chinese elements to their products. However, we cannot deny the fact that it may be because China's economic status has increased so those bands just want to attract more Chinese consumers.

The consumption atmosphere also plays a vital role in the spread of traditional Chinese culture. The formation of the consumer society has made the consumption function of the media prominent and strengthened, especially its entertainment function. Most media attach great importance to users, data, and attention. How to spread traditional culture 
professionally in the "entertainment-oriented" consumer society has become a major problem.

Additionally, the employment environment seriously affects the spread of traditional culture. In our country, traditional culture wither away at a speed faster than we can protect and inherent it. Many traditional cultures face the situation of no successors. There are fewer people engaged in traditional culture-related occupations and their level of education is relatively low. As we can see from the major settings, most university majors are science and engineering, economics and management, and literature and history. There are very few majors concerning traditional culture and craft learning. Even in vocational schools, there barely exists similar majors. From most people's point of view, only peasants or those who have a low level of education will be engaged in handcrafts, such as the production of ceramics. It can be seen that the employment prospects of traditional culture-related occupations are not optimistic.

\section{2) Cultural Environment}

With the continuous development of globalization, interactions between countries are increasingly frequent. Domestic traditional culture coexists with various foreign cultures. People are affected by more and more cultures and have more diverse values and cultural appeals. Therefore, traditional culture is more easily been neglected.

To a certain extent, the flood of foreign culture has squeezed the space of traditional culture promotion, distracting the attention of the people and disturbing the spread of traditional culture.

In today's consumer society, the fast-food culture prevails, and less and less audiences are willing to accept in-depth content. The complexity and diversity of traditional culture require definite focus and strong perseverance in learning. In today's society, most people do not or do not want to spend energy and time to learn traditional culture systematically.

\section{Measures to Eliminate the Predicament of TRADITIONAL CULTURAL COMMUNICATION}

\section{A. Improving Self-Communication}

\section{1) Modernization}

Traditional culture must be modernized in order to be better disseminated. The transformation needs to start from both content and form.

First, speaking of the content of communication, we must keep the essence and abandon the dross, conforming it to the development of the times. We should also mix traditional culture with the characteristics of the times, bringing traditional culture into modern life, and constantly innovating to create new highlights to maintain the vitality of traditional culture. For instance, the film Ne Zha, which is lately on show, has revolutionarily transferred the traditional figure $\mathrm{Ne} Z \mathrm{Zha}$ and added modern humor.

Second, in the form of communication, we must be good at spreading traditional culture through modern media. New media technologies have the advantages of high speed, efficiency, convenience and good interaction with the audience.
Traditional cultural communicators can use the new media platform to preserve and display traditional culture through such as Internet and video technology. For instance, a documentary, Masters in the Forbidden City, showed the public how hard and perseverant those masters are and gave us a chance to know more about our culture relics.

The modernization of traditional culture requires the help of new communication mechanisms, new forms of expression and new technologies. Nevertheless, the distinction between the essence and the less important must be clear. Focus should be on content. Too much element of entertainment is not what we want.

\section{2) Focusing on the needs of the people}

The modernization of traditional culture should be centered on the audience, their needs should be put to the first place, including material needs and spiritual satisfaction. With the continuous improvement of living standards, people's demand for culture is growing, and the willingness to explore traditional culture and enthusiasm for learning are also rising. Consumer's preferences become more personalized and diversified, which require traditional cultural communicators to respect the audience's subjective consciousness, and at the same time be able to consider the individualized needs of the audience.

During a long period, the promotion of traditional culture has been biased towards one-way communication to the public However, the two-way interactive propaganda is more acceptable in cultural communication. Only by infiltrating traditional culture into daily life can people feel and use traditional culture to promote communication, enhance cognition and enhance identity.

\section{B. Government Should Play a Positive Role}

The government should issue more policies to support traditional culture, do a better job in the protection and inheritance of traditional culture. So that our traditional culture can survive.

Additionally, in order to provide institutional guarantee for the spread of traditional culture, the government should enact laws and regulations in media communication. To implement certain supervision and strengthen supervision of online media is also important.

The government can also try to organize traditional cultural exchange activities. Those activities can be organized by relevant cultural units and promoted by mainstream media. To create a platform for traditional culture, the government can also invite professionals of related area to work together.

An effective government will play an important role in promoting the inheritance and dissemination of traditional culture

\section{Creating a Good Social Atmosphere}

First, schools should attach more importance to traditional culture and raise students' attention to traditional culture from an early age. Hopefully, to create more chances for the communication of traditional culture. 
The second is to promote the development of traditional cultural industries, so that they can have both economic and social benefits. By means of updating concepts, adapting new technologies, and adding their own characteristics to the product. Enterprises of traditional culture will grasp the market demand, improve the quality of products, establish a good image, and retain customers and fans.

The third is to improve the employment prospects of traditional culture. With the continuous development of the traditional cultural industry, more and more capital and talents will enter this market. How can we guarantee that they will get due reward? Apparently, besides the support of government, we also need make and obey regulations within the industry.

Only by realizing the above three points can we promote talent cultivation. When the condition of school's traditional culture education, cultural industry and market environment get better and better, more talents will choose vocation related to traditional culture. Thus, a virtuous circle of culture communication and industry development will take shape.

\section{CONCLUSION}

Our traditional culture covers many grounds, including bare necessities of life, folk customs, art culture, antiques, folk crafts, story resources, culture symbols and spiritual values. It also influences people's life, consciously or unconsciously.

Analysis in depth can help us take effective measures to get rid of the dilemma and promote the modern spread of traditional culture. The good dissemination of traditional culture can not only protect it, inherent it and revitalize it, but also inspire the development of cultural industry. By the means of modernization, traditional culture can be infused in our daily life, improving our life experience, conveying our aesthetic taste and personality, and providing us with wisdom and moral standard.

To sum up, we are unconsciously influenced by traditional culture; the food spread of it will bring us happier experience and stronger sense of belong.

\section{REFERENCES}

[1] Zhengrong $\mathrm{Hu}$ "On the trouble we have to spread traditional culture in modern society,” People's Tribune, vol. 26, pp. 134-135, 2017 (In Chinese)

[2] Lili Hao “On the spread of traditional culture with modern media," Youth Journalist, vol. 9, pp. 19-20, 2017 (In Chinese)

[3] Jingjun Pang “The original logic and modern transformation of Chinese traditional culture,” People's Tribune, vol. 34, pp.125-127,2017 (In Chinese)

[4] Huaiyun Chang "The dilemma of Chinese traditional culture's international communication,” A Vast View on Publishing, vol. 19, pp. 58-60,2017 (In Chinese)

[5] Xiaodong Zhuang, Xin Wen "The spread of Chinese traditional culture in new era,” Youth Journalist, vol. 9, pp. 9-12, 2017 (In Chinese)

[6] Weiguo Huang, Qiongqiong $\mathrm{Lu}$ "Discussion on the difficulties and countermeasures of Chinese traditional festival culture communication in front of new media,” Beauty\& Times, vol. 1, pp. 37-38, 2017 (In Chinese)

[7] Jie Ren "How to dig out the value of Chinese traditional culture in new time,” People's Tribune, vol. 34, pp. 134-135, 2017 (In Chinese) 